\title{
Satisfaction with e-participation: A Model from the Citizen's Perspective, Expectations, and Affective Ties to the Place
}

\author{
Mijail Naranjo Zolotov ${ }^{1(\bowtie)}{ }^{\text {, Tiago Oliveira }}{ }^{1}$, Frederico Cruz-Jesus ${ }^{1}$, \\ and José Martins ${ }^{2}$ \\ ${ }^{1}$ NOVA, Information Management School (NOVA IMS), Lisbon, Portugal \\ \{mijail.naranjo, toliveira, fjesus\}@novaims.unl.pt \\ ${ }^{2}$ INESC TEC and University of Trás-os-Montes e Alto Douro, \\ Vila Real, Portugal \\ jmartins@utad.pt
}

\begin{abstract}
The diffusion and adoption of e-participation contributes to better democracy and more participative societies. Nevertheless, despite the potential benefits of e-participation, the level of citizen satisfaction regarding the use of e-participation and its effects on the continued intention to use have not been widely assessed yet in the literature. This article proposes a conceptual model that integrates the DeLone \& McLean success model, that assesses the citizen satisfaction regarding the perception of the e-participation system quality; the expectation-confirmation model for the continued intention to use, which evaluates satisfaction based on the confirmation of ex-post experience on e-participation use and the perceived usefulness; and the dimensions of sense of place, which play a moderator role between the citizen satisfaction and the e-participation use.
\end{abstract}

Keywords: E-participation $\cdot$ Citizen satisfaction $\cdot$ DeLone \& McLean model Expectation-confirmation model $\cdot$ Sense of place

\section{Introduction}

The United Nations e-government survey 2014 [1] defines e-participation as "the process of engaging citizens through ICTs [information and communication technologies] in policy and decision-making in order to make public administration participatory, inclusive, collaborative and deliberative for intrinsic and instrumental ends". The successful implementation of e-participation can bring prominent benefits for the society [2], as for instance, transparency, efficiency, and better quality of public services, even reducing costs in democratic and decision-making processes [3]. These benefits are possible if a substantial number of citizens of a community or city adopt and use e-participation in the long-term. Therefore, the level of citizen satisfaction regarding the usage of e-participation is a crucial factor in the adoption of these technologies over time.

Citizen satisfaction with the use of e-participation and e-government systems has been proven to improve the trust in government $[4,5]$, and to have a direct influence in 
citizens' adoption and use behaviour of the system. For instance, in the context of e-government, a study by Foresee [6] found that highly satisfied citizens, compared to dissatisfied ones, are: $54 \%$ more likely to participate in democratic processes and express their opinions, $52 \%$ more likely to return to the system, $100 \%$ more likely to recommend the website to family and friends, and $63 \%$ more likely to trust the government agency. The United Nations e-government survey report 2012 [5] suggests that measuring citizens experience and satisfaction is still a challenge, highlighting the crucial importance for governments to improve the measurement methods and build assessment frameworks for citizens satisfaction. However, scant literature has assessed the citizen satisfaction of e-participation [7, 8]. This study proposes a conceptual model to fill this gap.

The main contribution of this study is the development of a conceptual model to evaluate citizens satisfaction with the use of e-participation systems, and the influence that the level of satisfaction plays for the continued intention to use e-participation. To achieve our goal, we propose integrating three well-known theories: The DeLone \& McLean (D\&M) success model [9], which measures satisfaction based on the perception of the e-participation system quality; the expectation-confirmation model (ECM) [10], which measures satisfaction based on the perception of confirmation that citizens have in the post adoption stage of e-participation; and finally, the dimensions of sense of place (SOP), which refer to the affective or meaning ties that a citizen may have for a place, which may strengthen the level of satisfaction when using e-participation systems.

The rest of the paper is organized as follows, Sect. 2 summarizes the insights from earlier studies and the potential effects of citizen satisfaction over e-participation and e-government initiatives. Section 3 develops the conceptual model and hypotheses proposed in this study. Section 4 provides a conclusion and suggestions for future research.

\section{Citizen Satisfaction}

Most earlier studies have measured citizen satisfaction regarding government services performance $[11,12]$, finding that citizen satisfaction mainly depends on their performance perception, which may also be influenced by external factors. The overall citizen satisfaction may be an important factor in the prediction of behavioural responses, such as trusting the government [13] or influencing the adoption of e-government [14]. However, in the case of e-participation platforms, where the citizens may be directly involved in the decision-making process, it is not yet clear what the main drivers of citizen satisfaction are.

In the context of the e-government mandatory services, Chan et al. [15] evaluated the four main determinants of the unified theory of acceptance and use of technology (UTAUT) [16] (performance expectancy, effort expectancy, social influence, and facilitating conditions) as predictors of satisfaction. They found that all those determinants, except social influence, positively influenced the level of citizen satisfaction. Other studies have measured citizen satisfaction with e-government services using three dimensions of services quality: responsiveness, reliability, and empathy [14]. 
Nevertheless, in the case of e-participation, which is used voluntarily [17], the perception of satisfaction may differ from other systems because the final perceived outcomes and benefits for the community are influenced directly by the interactions of the citizens with the e-participation.

Satisfaction is a variable that has been widely measured in different fields of information and communication technology. A variety of research models and variables have been employed across the literature to measure and understand satisfaction. Two of the most used theoretical models for this purpose are D\&M [9] and ECM [10]. For instance, D\&M model was used by Tam and Oliveira [18] to study user satisfaction in the context of mobile banking; and by Akter et al. [19] to assess the service quality of mobile health applications. In the case of ECM, it was employed to evaluate the continuance intention to use the smartphone banking services, having user satisfaction as one of the dependent variables [20]; and also, for the study of satisfaction and continuous intention to use mobile instant messaging [21].

The implementation of e-participation systems by local governments has been proven to increase the level of citizen satisfaction [22], and in turn, citizen satisfaction positively impacts the level of trust in government [23, 24]. Furthermore, citizen satisfaction has been found to be the strongest predictor of the intention to use electronic services from the government, even stronger than perceived usefulness and perceived ease of use [14]. A study across 32 European countries found evidence of a positive association between e-participation performance and citizen satisfaction [25].

\section{Conceptual Model and Hypotheses}

Our study adopts the updated version of the D\&M success model [9], the objective of which is to assess citizen satisfaction and e-participation usage. Six constructs define the D\&M model: information quality, system quality, service quality, use, citizen satisfaction, and net benefits. The net benefits refer to the benefits obtained by the organization that adopts the information system (IS). However, in the e-participation context the final beneficiary is a community of citizens. Consequently, we have dropped this construct from our model.

The ECM analyses citizen satisfaction as the result of the confirmation from prior use of an ICT and the perceived usefulness. The final goal of the expectationconfirmation model is to explain the continuance intention of an ICT, in our case, e-participation. We adopt the model of information system continuance proposed by Bhattacherjee [10], which is composed of four constructs: perceived usefulness, confirmation, satisfaction, and e-participation continuance intention. The ECM sequence of e-participation adoption can be summarized as: (i) the citizen makes an initial acceptance decision, (ii) the citizen has an initial experience with e-participation, (iii) the citizen makes an ex-post decision regarding whether to continue using e-participation or reverse the initial decision.

In the context of public services, Van Ryzin [26] suggests that citizens judge public services not only on the perceived quality of the information system, but also on an implicit comparison with prior expectations. E-participation systems can be considered public services provided by local or national governments, in this sense, the integration 
of D\&M model with ECM may provide a bigger picture of the factors that may explain citizen satisfaction and continuous intention to use e-participation. Moreover, since e-participation is voluntary and with the goal to bring benefits to a community, SOP [27] may have roles to play as moderators between use and citizen satisfaction. Figure 1 presents the conceptual model.

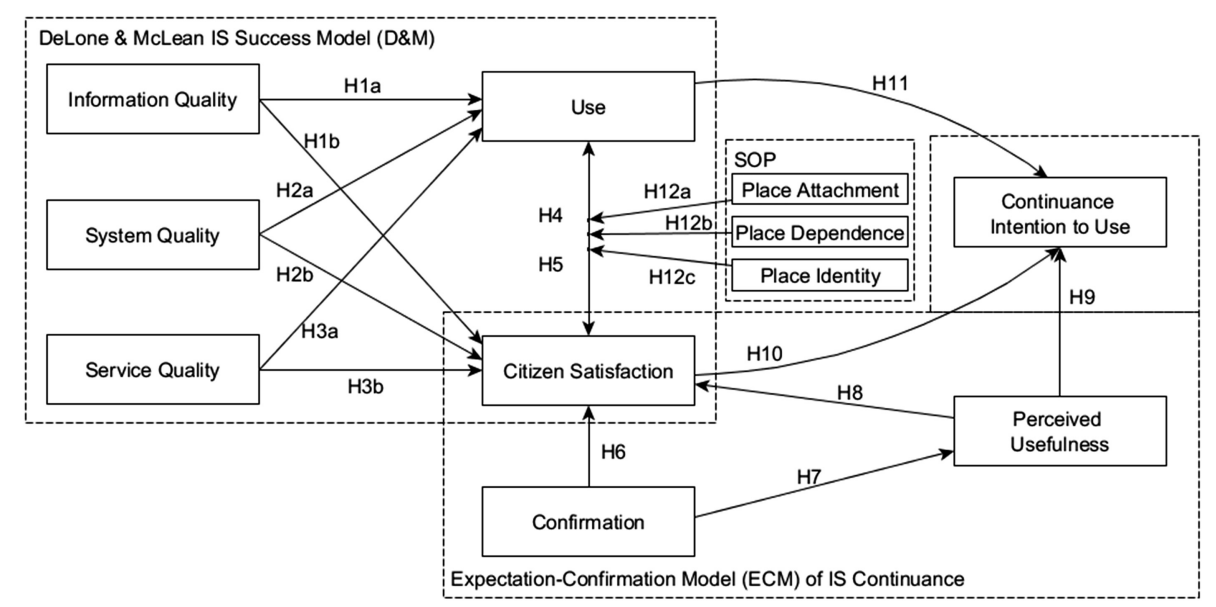

Fig. 1. Conceptual model

\subsection{DeLone and McLean Variables}

Teo et al. [28] define information quality as each citizen's assessment of whether the information on the e-participation website is accurate, valid, and timely. DeLone and McLean [9] identify five success metrics for information quality: completeness, ease of understanding, personalization, relevance, and security. In the e-participation context the information presented on the website is generated by both the government and the citizens. The government presents information about the objectives, process description, and feedback, which is essential to engage the citizens on e-participation and keep them using the system in the long term. At the same time, because the interaction of citizens on e-participation also generates information (e.g. discussion forums, project proposals), the improper presentation design of this information on the website may create barriers for the citizen interaction on e-participation. For instance, in online participatory budgeting processes [29] it is expected that the information available on each project proposal is complete and can be easily found on the website in order for the citizens to have a clear idea about which project to vote for. Lack of clarity and 
consistency may cause citizen frustration and consequently increase absenteeism in the voting process, and stop or decrease the use of the e-participation platform. Therefore, we hypothesize:

H1a. Information quality has a positive influence on the use of e-participation.

H1b. Information quality has a positive influence on the citizen satisfaction of e-participation.

System quality is defined as the individual perception of the system's overall performance [9], which in turn may lead to greater user satisfaction and use of the information system. In the e-participation context the overall system quality may be judged by the degree to which a citizen is able to contribute to an online participatory process (e.g. electronic voting, proposal submission, opinion giving). A citizen perception about the e-participation overall quality may be initially linked to the trust in the local government that manages the system [28]. As e-participation is made available to all the citizens in a given community, the system quality can be measured in terms of usability, ease of use, accessibility, reliability, feedback, transparency, and so on. For instance, using the same e-participation example used for information quality (the online participatory budgeting), citizens who provided an electronic vote for a project may be interested in having access to a detailed report of the voting results shortly after the voting period is over. Failing to provide the final voting results in a reasonable time may affect the perception of transparency and trust in the e-participation system, and thus, negatively impact the citizens perception of overall system quality. We hypothesize:

$\mathrm{H} 2 \mathrm{a}$. System quality has a positive influence on the use of e-participation.

$\mathrm{H} 2 \mathrm{~b}$. System quality has a positive influence on the citizen satisfaction of e-participation.

DeLone and McLean [9] define "service quality is the overall support delivered by the service provider". According to Teo et al. [28], in the context of e-government, service quality is perceived as interaction between citizens and government officials. However, in e-participation the existing interactions are both between citizens and governments and between citizens and citizens. Government officials behind the online participatory platforms are expected to keep the information updated, provide feedback, and/or regulate inappropriate content generated by citizens. In turn, citizens are the core-content generators in e-participation, for instance, providing opinions in online forums or submitting proposals for the online participatory budgeting. Poor service quality from the government side may lead to poor citizen participation, and consequently, poor content generated by citizens may lead to demotivate other citizens from using e-participation.

H3a. Service quality has a positive influence on the use of e-participation.

H3b. Service quality has a positive influence on the citizen satisfaction of e-participation.

DeLone and McLean [9] suggest that citizen satisfaction and usage of e-participation are closely interrelated, in which a positive experience in use may lead to a positive citizen satisfaction. Wang and Liao [30] note that the use of e-participation 
systems is completely voluntary, and suggest that actual use has a closer meaning to success than intention to use. We follow the approach of Wang and Liao [30] and adopted use as a success measure in the context of e-participation for our conceptual model. On the opposite direction, greater citizen satisfaction has also being found to positively affect use of e-participation [18]. Therefore, we hypothesize:

H4. The use affects the citizen satisfaction on e-participation.

H5. The citizen satisfaction affects the use of e-participation.

\subsection{Expectation-Confirmation Variables}

Bhattacherjee [10] refers to confirmation as the "realization of the expected benefits of IS use". In the EMC for continuous use, expectation is represented by perceived usefulness, which also suggests that perceived usefulness can be adjusted according to the citizen confirmation experience. Earlier studies have found a positive influence of confirmation over satisfaction and perceived usefulness [20, 21, 31]. Since e-participation platforms are oriented to the citizenry and managed by the governments, they are planned to last for several years (e.g., online participatory budgeting and incident reporting applications) before being changed or replaced. Therefore, it is expected that citizens who experience e-participation can adjust their perception of usefulness over time based on the confirmation experience.

H6. Confirmation positively influences the citizen satisfaction with e-participation.

H7. Confirmation positively influences the perceived usefulness of e-participation.

In the job context, perceived usefulness is defined as the individual belief that using the ICT will help to increase one's job performance [32]. For the context of e-participation, perceived usefulness can be interpreted as the perception of the citizen that using e-participation will help to make a better or more effective contribution to the community. According to Bhattacherjee [10], perceived usefulness may affect citizen satisfaction in both phases: acceptance and post-acceptance. Due to the long-term vision of e-participation, perceived usefulness becomes an especially suitable factor to analyse citizen satisfaction in this context. Earlier studies report that perceived usefulness positively affects citizens satisfaction and continuance intention to use [20, 21]. Continuance intention to use is defined as the degree to which citizens perceive that they will continue using e-participation in the future [33].

H8. Perceived usefulness positively influences the citizen satisfaction with eparticipation.

H9. Perceived usefulness positively influences the citizen continuance intention to use e-participation.

Citizen satisfaction with prior use of e-participation has been found to be one of the strongest predictors of continuance intention to use in several fields of ICT adoption; for instance, on university information systems [34], mobile internet [31], mobile banking [20], and mobile instant messaging [21]. As e-participation systems are intended to be used in the long term, their frequent use over time may also positively influence the continuance intention to use. Therefore, we hypothesize: 
H10. The level of citizen satisfaction positively influences the continuance intention to use e-participation.

H11. The use of e-participation positively affects the continuance intention to use e-participation.

\subsection{Moderator Role of Sense of Place (SOP)}

SOP has been defined as "the meaning attached to a spatial setting by a person or group" [27]. Considering that the most e-participation projects implemented by government are at city or parish level (e.g., participatory budgeting, incident reporting applications), the ties that a citizen has to a place may significantly affect her/his behaviour regarding the use of e-participation when that place is involved. Acedo et al. [35] suggest that geographical areas containing a higher level of SOP may create better conditions for "cooperation and collaborative synergies between people who share more than just a space". SOP is encompassed and measured in three dimensions [36]: place attachment, place dependence, and place identity. Place attachment is defined as an emotional bond that citizens develop with some geographical place [37]. Earlier literature has found that place attachment positively affects the neighbourhood ties of a citizen [38]. Place dependence refers to the useful values that a place may have to satisfy the citizens' goals and desires in comparison to other places [39]. Place identity is conceived as the reflection of the citizen regarding a place [36], also defined as an expression of "at homeness" [40]. We include the three components of SOP in our conceptual model as moderatos of the relationship between the use of e-participation and citizen satisfaction. We posit that the stronger the feeling of SOP to a certain area, the higher the level of satisfaction when the interaction on e-participation involves that area.

H12a. Place attachment moderates the effect of use of e-participation over citizen satisfaction, in which the citizen satisfaction is greater when the feeling of place attachment is stronger.

H12b. Place dependence moderates the effect of use of e-participation over citizen satisfaction, in which the citizen satisfaction is greater when the feeling of place dependence is stronger.

H12c. Place identity moderates the effect of use of e-participation over citizen satisfaction, in which the citizen satisfaction is greater when the feeling of place identity is stronger.

\section{Implications and Future Research}

On e-participation context, citizen satisfaction is a complex variable, challenging to measure from the citizen's perspective. Van Ryzin [11] points out that exogenous variables to the information systems (IS) itself may impact on the performance perception and satisfaction of the citizens. Our model presents a wholistic approach that not only measures the perception of quality of the online information system (e.g., navigability or functionality of the e-participation website [6]). But also attempts to provide a better understanding of the citizen satisfaction from the perspective of perceived usefulness. 
Governments that implement e-participation, may use our model to evaluate citizen satisfaction and design policies of continuous improvement and evolution of e-participation tools, considering not only the improvement of the system quality, but also addressing the effect of external factors and citizens' perceived usefulness. Thus, achieving higher levels of citizen satisfaction in the long-term scenario. The continuous evaluation of citizen satisfaction may be crucial to prevent the risk, for governments, that citizens may generalize a non-satisfactory experience using e-participation to a feeling of distrust on the governmental institution [41]. Governments may use the model to monitor the level of citizens satisfaction periodically and adjust the policies on time before the citizens loose interest on the e-participation platforms.

Measuring sense of place and its effect on citizen satisfaction may facilitate to refine e-participation tools to create a bigger impact at local community level as neighbourhoods or parishes. For instance, to promote the use of participative budgeting platforms, the diffusion campaigns may be tailored to the local communities depending of the levels of sense of place.

Satisfied citizens with the continued use of e-participation may also be more willing to engage in democratic processes and try new e-participation initiatives proposed by the local governments. Consequently, by identifying high levels of citizen satisfaction, governments may identify the most appropriate period to promote new e-participation tools.

Future research may evaluate the proposed model by collecting data from citizens that have experienced e-participation systems, and either are still using the system or have discontinued the usage of e-participation. Using evaluation methods like structural equation modelling [42], we can obtain results about the strength of the conceptual factors as drivers of citizen satisfaction, use, and continued intention to use e-participation.

\section{Conclusion}

Citizen satisfaction is a critical factor that influences the e-participation adoption in the long term. Once the citizens reach a high level of satisfaction with e-participation use, additional side benefits come along with satisfaction, such as trust in government and increased willingness to participate in democratic processes. The assessment of citizen satisfaction on e-participation use is still a challenge for research and for governments that want to implement successful e-participation projects. E-participation is of a voluntary use, accessible and inclusive to all citizens, is managed and sponsored by the government, and the information on the system is mainly generated by the citizens for the citizens. The assessment of the level of citizen satisfaction should consider all these characteristics. We propose a conceptual model to evaluate citizen satisfaction with e-participation. The model integrates the DeLone \& McLean success model, which measures the satisfaction in terms of perception of quality, the expectation-confirmation model, which measures satisfaction based on the confirmation and perceived usefulness, and finally, the sense of place, which refers to emotional and meaning ties that the citizen has to a specific area, which may moderate the effect of satisfaction over e-participation use. 
Acknowledgment. Mijail Naranjo Zolotov gratefully acknowledge the support of Geo-informatics: Enabling Open Cities (GEO-C), the project funded by the European Commission within the Marie Skłodowska-Curie Actions, International Training Networks (ITN), and European Joint Doctorates (EJD). Grant Agreement number 642332 - GEO-C - H2020-MSCA-ITN-2014.

\section{References}

1. United Nations: E-government survey 2014 E-government for the future we want. New York, USA (2014)

2. Royo, S., Yetano, A.: "Crowdsourcing" as a tool for e-participation: two experiences regarding CO2 emissions at municipal level. Electron. Commer. Res. 15, 323-348 (2015). https://doi.org/10.1007/s10660-015-9183-6

3. Vragov, R., Kumar, N.: The impact of information and communication technologies on the costs of democracy. Electron. Commer. Res. Appl. 12, 440-448 (2013). https://doi.org/10. 1016/j.elerap.2013.06.003

4. Bélanger, F., Carter, L.: Trust and risk in e-government adoption. J. Strateg. Inf. Syst. 17, 165-176 (2008). https://doi.org/10.1016/j.jsis.2007.12.002

5. United Nations: E-Government Survey 2012 E-government for the People (2012)

6. Foresee: Foresee e-government satisfaction index Q1 2016 (2016)

7. Kipenis, L., Askounis, D.: Assessing e-participation via user's satisfaction measurement: the case of OurSpace platform. Ann. Oper. Res. 247, 599-615 (2016). https://doi.org/10.1007/ s10479-015-1911-8

8. Naranjo Zolotov, M., Oliveira, T., Casteleyn, S.: E-participation adoption models research in the last 17 years: a weight and meta-analytical review. Comput. Hum. Behav. 81, 350-365 (2018). https://doi.org/10.1016/j.chb.2017.12.031

9. DeLone, W.H., McLean, E.R.: The DeLone and McLean model of information system success: a ten-year update. J. Manage. Inf. Syst. 19, 9-30 (2003). https://doi.org/10.1073/ pnas.0914199107

10. Bhattacherjee, A.: Understanding information systems continuance: an expectationconfirmation model. MIS Q. 25, 351-370 (2001). https://doi.org/10.2307/3250921

11. Van Ryzin, G.G.: Pieces of a puzzle: linking government performance, citizen satisfaction, and trust. Public Perform. Manage. Rev. 30, 521-535 (2007). https://doi.org/10.2753/ PMR1530-9576300403

12. Van Ryzin, G.G.: Testing the expectancy disconfirmation model of citizen satisfaction with local government. J. Public Adm. Res. Theory 16, 599-611 (2005). https://doi.org/10.1093/ jopart/mui058

13. Venkatesh, V., Thong, J.Y.L., Chan, F.K.Y., Hu, P.J.H.: Managing citizens' uncertainty in e-government services: the mediating and moderating roles of transparency and trust. Inf. Syst. Res. 27, 87-111 (2016). https://doi.org/10.1287/isre.2015.0612

14. Al Hujran, O., Aloudat, A., Altarawneh, I.: Factors influencing citizen adoption of e-government in developing countries. Int. J. Technol. Hum. Interact. 9, 1-19 (2013). https:// doi.org/10.4018/jthi.2013040101

15. Chan, F.K.Y., Thong, J.Y.L., Venkatesh, V., et al.: Modeling citizen satisfaction with mandatory adoption of an e-government technology. J.Assoc. Inf. Syst. 11, 519-549 (2010)

16. Venkatesh, V., Morris, M.G., Davis, G.B., Davis, F.D.: User acceptance of information technology: toward a unified view. MIS Q. 27, 425-478 (2003). https://doi.org/10.2307/ 30036540 
17. Medaglia, R.: eParticipation research: moving characterization forward (2006-2011). Gov. Inf. Q. 29, 346-360 (2012). https://doi.org/10.1016/j.giq.2012.02.010

18. Tam, C., Oliveira, T.: Understanding mobile banking individual performance the DeLone \& McLean model and the moderating effects of individual culture. Internet Res. 27, 538-562 (2017). https://doi.org/10.1108/IntR-05-2016-0117

19. Akter, S., D'Ambra, J., Ray, P.: Service quality of mHealth platforms: development and validation of a hierarchical model using PLS. Electron. Mark. 20, 209-227 (2010). https:// doi.org/10.1007/s12525-010-0043-X

20. Susanto, A., Chang, Y., Ha, Y.: Determinants of continuance intention to use the smartphone banking services. Ind. Manage. Data Syst. 116, 508-525 (2016). https://doi.org/10.1108/ IMDS-05-2015-0195

21. Oghuma, A.P., Libaque-Saenz, C.F., Wong, S.F., Chang, Y.: An expectation-confirmation model of continuance intention to use mobile instant messaging. Telemat Inform. 33, 34-47 (2016). https://doi.org/10.1016/j.tele.2015.05.006

22. Ahn, M.J., Bretschneider, S.: Politics of e-government: E-government and the political control of bureaucracy. Public Adm. Rev. 71, 414-424 (2011). https://doi.org/10.1111/j. 1540-6210.2011.02225.x

23. Christensen, T., Lægreid, P.: Trust in government: the relative importance of service satisfaction, political factors, and demography. Public Perform. Manage. Rev. 28, 487-511 (2005). https://doi.org/10.1080/15309576.2005.11051848

24. Welch, E.W.: Linking citizen satisfaction with e-government and trust in government. J. Public Adm. Res. Theory 15, 371-391 (2004). https://doi.org/10.1093/jopart/mui021

25. Ma, L., Zheng, Y.: National e-government performance and citizen satisfaction: a multilevel analysis across European countries. Int. Rev. Adm. Sci. 1-21 (2017). https://doi.org/10. 1177/0020852317703691

26. Van Ryzin, G.G.: An experimental test of the expectancy-disconfirmation theory of citizen satisfaction. J. Policy. Anal. Manage. 32, 597-614 (2013). https://doi.org/10.1002/pam. 21702

27. Jorgensen, B.S., Stedman, R.C.: Sense of place as an attitude: lakeshore owners attitudes toward their properties. J. Environ. Psychol. 21, 233-248 (2001). https://doi.org/10.1006/ jevp.2001.0226

28. Teo, T.S.H., Srivastava, S.C., Jiang, L.: Trust and electronic government success: an empirical study. J. Manage. Inf. Syst. 25, 99-132 (2009). https://doi.org/10.2753/MIS07421222250303

29. Allegretti, G., Antunes, S.: The Lisbon Participatory Budget: results and perspectives on an experience in slow but continuous transformation. F. Actions Sci. Reports. 11, 0-10 (2014)

30. Wang, Y., Liao, Y.: Assessing eGovernment systems success: a validation of the DeLone and McLean model of information systems success. Gov. Inf. Q. 25, 717-733 (2008). https://doi.org/10.1016/j.giq.2007.06.002

31. Hong, S., Thong, J.Y.L., Tam, K.Y.: Understanding continued information technology usage behavior: a comparison of three models in the context of mobile internet. Decis. Support Syst. 42, 1819-1834 (2006). https://doi.org/10.1016/j.dss.2006.03.009

32. Bhattacherjee, A., Premkumar, G.: Understanding changes in belief and attitude toward information technology usage: a theoretical model and longitudinal test. MIS Q. 28, 229254 (2004)

33. Hoehle, H., Venkatesh, V.: Mobile application usability: conceptualization and instrument development. MIS Q. 39, 435-472 (2015)

34. Liao, C., Palvia, P., Chen, J.L.: Information technology adoption behavior life cycle: toward a Technology Continuance Theory (TCT). Int. J. Inf. Manage. 29, 309-320 (2009). https:// doi.org/10.1016/j.ijinfomgt.2009.03.004 
35. Acedo, A., Painho, M., Casteleyn, S.: Place and city: operationalizing sense of place and social capital in the urban context. Trans. GIS 21, 503-520 (2017). https://doi.org/10.1111/ tgis. 12282

36. Jorgensen, B.S., Stedman, R.C.: A comparative analysis of predictors of sense of place dimensions: attachment to, dependence on, and identification with lakeshore properties. J. Environ. Manage. 79, 316-327 (2006). https://doi.org/10.1016/j.jenvman.2005.08.003

37. Lewicka, M.: Place attachment: how far have we come in the last 40 years? J. Environ. Psychol. 31, 207-230 (2011). https://doi.org/10.1016/j.jenvp.2010.10.001

38. Lewicka, M.: Ways to make people active: the role of place attachment, cultural capital, and neighborhood ties. J. Environ. Psychol. 25, 381-395 (2005). https://doi.org/10.1016/j.jenvp. 2005.10.004

39. Stedman, R.C.: Toward a social psychology of place: predicting behavior from place-based cognitions, attitude, and identity. Environ. Behav. 34, 561-581 (2002). https://doi.org/10. 1177/0013916502034005001

40. Cuba, L., Hummon, D.M.: A place to call home: identification with dwelling, community and region. Sociol. Q. 34, 111-131 (1993). https://doi.org/10.1111/j.1533-8525.1993. tb00133.x

41. Petrovsky, N., Mok, J.Y., León-Cázares, F.: Citizen expectations and satisfaction in a young democracy: a test of the expectancy-disconfirmation model. Public Adm. Rev. 77, 395-407 (2017). https://doi.org/10.1111/puar.12623

42. Hair, J., Hult, T., Ringle, C., Sarstedt, M.: A primer on partial least squares structural equation modeling (PLS-SEM), 1st edn. SAGE Publications, Thousand Oaks (2014) 